

\section{Sumário}

I. Crônicas do Direito Internacional ...............................................1

REPARAÇÃo DE VÍTIMAS À LUZ DE UM TRATAdo SOBRE EMPRESAS E DIREITOS HUMANOS ............ 3 Ana Cláudia Ruy Cardia

Consumer Social Responsibility as a Requirement for Corporate Social ResponsibiliTY

Nitish Monebhurrun

Crisis in Venezuela: The Brazilian response to the massive flow of Venezuelans in

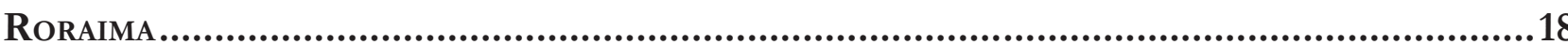

Jacqueline Salmen Raffoul

II. Dossiê EsPecial: Business and Human Rights.........................................23

Some remarks on the third sessions of the Business and Human Rights Treaty Pro-

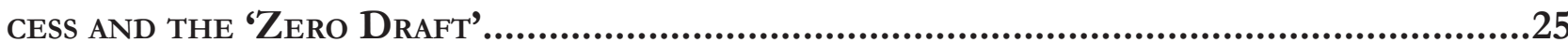

Humberto Cantú Rivera

The United Nations guiding principles on business and human Rights, the State

DUTY TO PROTECT HUMAN RIGHTS AND THE STATE-BUSINESS NEXUS.

Mihaela Maria Barnes

HARdening SOFT LAW: ARE THE EMERging Corporate SOCIAL DisClOSURE LAWS CAPABLE OF GENERATING SUBSTANTIVE COMPLIANCE WITH HUMAN RIGHTS?

Justine Nolan

Del Documento de Elementos al Draft 0: apuntes jurídicos respecto del posible CONTENIDO DEL PROYECTO DE INSTRUMENTO VINCULANTE SOBRE EMPRESAS TRANSNACIONALES

Y OTRAS EMPRESAS CON RESPECTO A LOS DERECHOS HUMANOS

Adoración Guamán 
ACCESS TO REMEDIES AND THE EMERGING ETHICAL DILEMMAS: CHANGING CONTOURS WITHIN THE BUSINESS-HUMAN RIGHTS DEBATE

Justin Jos

LA RESPONSABILIDAD PENAL DE LAS EMPRESAS POR GRAVES VIOLACIONES DE DERECHOS HUMANOS: PRÁCTICA ACTUAL Y DESAFÍOS FUTUROS 130

Daniel Iglesias Márquez

THE ENVIRONMENTAL LAW DIMENSIONS OF AN INTERNATIONAL BINDING TREATY ON BUSINESS AND HUMAN RIGHTS

Juan Gabriel Auz Vaca

Los Objetivos de Desarrollo Sostenible en Europa y su Intersección con el Marco de los Negocios y los Derechos Humanos

Paolo Davide Farah

HumAN RIGHTS AND MARKET ACCESS 203

Danielle Mendes Thame Denny

BusinesS AND HUMAN RIGHTS IN BRAZIL: EXPLORING HUMAN RIGHTS DUE DILIGENCE AND OPERATIONAL-LEVEL GRIEVANCE MECHANiSMS IN THE CASE OF KinRoss PARACATU Gold Mine...222 Mariana Aparecida Vilmondes Türke

Human Rights and eXtractive industries in Latin America: What Responsibility of CORPORATIONS AND THEIR STATES OF ORIGIN FOR HUMAN RIGHTS VIOLATIONS IN THE INTER-American Human Rights System?.

Alberto do Amaral Junior e Viviana Palacio Revello

MultinaCiOnAIS FAST FASHION E DIREITOS HUMANOS: EM BUSCA DE NOVOS PADRÕES DE RESPONSABILIZAÇÃO 255

Laura Germano Matos e João Luis Nogueira Matias

III. Artigos sobre outros temas

EFFICIENCY AND EFFICACY OF PUBLIC FOOD PROCUREMENT FROM FAMILY FARMERS FOR SCHOOL FEEDING IN BRAZIL. 271

Rozane Márcia Triches 
A relaÇão ENTRE O GRAU de INTEGRaÇÃo ECONÔMiCA E O SISTEMA DE SOLUÇÃo DE CONTROvÉRSIAS: UM ESTUdo COMPARATIVO ENTRE A UNIÃo EURopeia E O MERCOSUl.....................286

Luciane Klein Vieira e Elisa Arruda

THE RIGHTS TO MEMORY AND TRUTH IN THE INTER-AMERICAN PARADIGMS OF TRANSITIONAL JUSTICE: THE CASES OF BRAZIL AND CHILE 308

Bruno Galindo

Juliana Passos de Castro

A margem nacional de apreciação na Corte Interamericana de Direitos Humanos.325 Gilberto Schäfer, José Eduardo Aidikaitis Previdellie e Jesus Tupã Silveira Gomes

Novos Direitos FUNDAMENTAIS NO ÂMBITo DA UNASUL: ANÁLISE DAS AGENDAS DE Brasil E VENEZUELA À LUZ DO DIREITO À PAZ.

Pedro Pulzatto Peruzzo e Arthur Ciciliati Spada

A atuação do Grupo Mercado Comum frente À Criminalidade organizada transnacio-

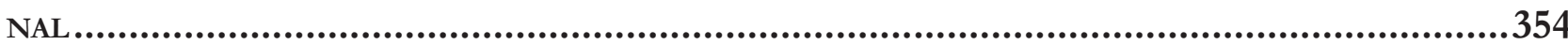

Sabrina Cunha Kesikowski, Luis Alexandre Carta Winter e Eduardo Biacchi Gomes

COUNTER-TERRORISM LEGISLATION AND TERRORIST ATTACKS: DOES HUMAN RIGHTS HAVE SPACE?

Heloisa Tenello Bretas e Daniel Damásio Borges

Territórios da ViolênCia de GÊNERo: NORMATIVA INTERNACIONAL E os Casos "CAMpo AlGodoeiro” (MÉXICO) - “Morro do Garrote” (BrasiL)

Eugênia Nogueira do Rêgo Monteiro Villa e Bruno Amaral Machado

O USO DE MECANISMOS INFORMAIS DE GOVERNANÇA GLOBAL E SUA APLICABILIDADE NAS LICITAÇÕES PÚBLICAS BRASILEIRAS.

Fabiano de Figueiredo Araujo e Paulo Afonso Cavichioli Carmona

Autonomia INSTITUCIONAL DA IGREJA CATÓliCA E A INGERÊNCIA INDEVIDA DO ESTADO BRASILEIRo POR EVENTUAIS Ilícitos CANÔNicos: ANÁlise do CASO de Formosa-GO, À luz do TraTADo Brasil-Santa SÉ de 2010 
A MORE TARGETED APPROACH TO FOREIGN DIRECT INVESTMENT: THE ESTABLISHMENT OF SCREENING SYSTEMS ON NATIONAL SECURITY GROUNDS

Carlos Esplugues Mota

IV. RESENHAS 467

Direito Internacional em Perspectiva Transcivilizacional de Yasuaki Onuma........469 Arthur Roberto Capella Giannattasio

Resenha do livro Space, Global Life: The Everyday Operation of International LaW and Development, de Luis Eslava .473

Matheus Gobbato Leichtweis

QUEM TEM MEDO DO PÓS-COLONIAL NO DIREITO INTERNACIONAL? UMA RESENHA DE "DECOLONISING INTERNATIONAL LAW: DEVELOPMENT, ECONOMIC GROWTH AND THE POLITICS OF UNIVERSAlity" de Sundhya Pahuja

Gabriel Antonio Silveira Mantelli

Direitos humanos COMO UM NOVO PROJETO PARA O Direito INTERNACIONAL? Notas sobre The Last Utopia, de Samuel Moyn .490 João Roriz 


\title{
Resenha do livro Space, Global Life: The Everyday Operation of International Law and Development, de Luis Eslava*
}

\author{
Matheus Gobbato Leichtweis**
}

\section{Resumo}

O objetivo desta resenha é apresentar ao público brasileiro o livro Local Space, Global Life. The Everyday Operation of International Law and Development, de Luis Eslava. Com foco nas recentes transformações urbanas ocorridas na cidade de Bogotá, Local Space, Global Life busca compreender de que maneira as prescrições normativas do direito internacional, em conjunto com o projeto internacional de desenvolvimento, operam e se materializam, hoje, no nível das jurisdições locais, reconstituindo os espaços urbanos e influenciando o dia a dia das populações urbanas periféricas, principalmente do Terceiro Mundo. Nesse contexto, a presente resenha tem por escopo apresentar os principais argumentos veiculados ao longo do livro, com enfoque para o inovador método (antropológico e etnográfico) desenvolvido pelo autor para abordar a recente expansão do direito internacional na direção de múltiplas camadas da vida social e material das grandes cidades. Por fim, diante da constatação de que a obra apresenta um novo olhar sobre o direito internacional (um olhar menos institucional e estadocêntrico, e mais comprometido com a vida real, subjetiva e material das pessoas comuns), a resenha busca destacar a relevância da obra para a crítica contemporânea do direito internacional, especialmente a crítica veiculada a partir do Terceiro Mundo.

Palavras-chave: Direito internacional. Desenvolvimento. Descentralização. Jurisdições locais. Bogotá.

\section{Abstract}

The aim of this review is to present the book Local Space, Global Life. The Everyday Operation of International Law and Development, by Luis Eslava, to the Brazilian readership. Focusing on the recent urban transformations of the city of Bogotá, Local Space, Global Life seeks to understand the ways in which the normative prescriptions of international law, together with the international development project, are, today, being materialized at the level of local jurisdictions, recreating the urban spaces and influencing the everyday lives of peripheral urban residents, particularly in the Third World. In this context, the review presents the main arguments advanced in the book, with a special emphasis on the method developed by Eslava to understand the recent expansion of international law towards multiple realms of social and material life: the anthropological and ethnographic approach to international law. Finally, the review concludes that Eslava's new method (a more

grounded approach to the subject, less institutionalized and state-centric

** Graduado em Direito pela Pontifícia Universidade Católica do Rio Grande do Sul (PUCRS). Possui mestrado (LLM) em Direito Ambiental, obtido com mérito junto à Univeridade de Dundee (University of Dundee), Escócia, Reino Unido. Atualmente, é mestrando em Direito Internacional pela Universidade Federal do Rio Grande do Sul (UFRGS). Email: matheusglei@gmail.com 
and more committed to the real, material and subjective lives of ordinary people), represents a real innovation in terms of a Third World critique to international law.

Keywords: International law. Development. Decentralization. Local jurisdictions. Bogotá.

\section{INTRODUÇão}

Professor da Kent Law School, Luis Eslava se destaca como um dos mais prestigiados acadêmicos da nova geração de estudos críticos do direito internacional. Esse papel de destaque foi consolidado a partir da publicação, no ano de 2015, do livro 'Local Space, Global Life. The Everyday Operation of International Law and Development", fruto dos estudos de $\mathrm{PhD}$ do autor na Melbourne Law School, que rendeu ao autor os prêmios "Hart Socio-Legal Book Prize" e o "Prize for Early Career Academics", conferidos pela Socio-legal Studies association (SLSA), "in recognition of outstanding socio-legal scholarship".

Com foco nas recentes transformações urbanas ocorridas na cidade de Bogotá, o livro objeto desta resenha busca compreender, com base em uma perspectiva antropológica e etnográfica, de que maneira as prescrições normativas do direito internacional, em conjunto com o projeto internacional de desenvolvimento, operam e se materializam no nível das jurisdições locais, reconstituindo os espaços urbanos e influenciando o dia a dia das populações urbanas periféricas, principalmente do Terceiro Mundo. O livro lida com dois problemas fundamentais relacionados à ordem legal, política e econômica global contemporânea: por um lado, explora as implicações do aumento da relevância das cidades (jurisdições locais) no cenário internacional (um fenômeno que é reflexo da crise do estado-nação e da ascensão de novos atores internacionais no contexto da globalização, bem como da recente tendência à descentralização dos esforços de desenvolvimento no terceiro mundo); e, por outro lado, se dedica à elaboração de um método adequado para compreender o complexo processo de formação global — que se dá, hoje, não somente em nível internacional (no âmbito das relações interestatais, das instituições e das normas internacionais), mas também em nível local, na medida em que as legislações nacionais e municipais tendem a incorporar os preceitos e ideais da globalização para a construção de seus espaços urbanos e para significação dos sujei- tos que os habitam. É por entender que a obra possui, conforme se pretende demonstrar, extrema relevância para o estudo crítico do direito internacional (sobretudo no âmbito da crítica de Terceiro Mundo da disciplina, ainda incipiente na academia brasileira), que a presente resenha tem por escopo apresentar a obra "Local Space, Global Life" ao público brasileiro.

\section{Desenvolvimento}

\subsection{Argumento principal e objetivos}

Em Local Space, Global Life, Luis Eslava apresenta os resultados de uma década de pesquisa acerca da relação entre direito internacional e o projeto de desenvolvimento. Em suma, o livro procura compreender como o direito internacional (suas instituições, normas e discursos associados à ideia de desenvolvimento) se expandiu nos últimos anos - como resultado da tendência à descentralização do desenvolvimento no Terceiro Mundo — na direção de múltiplas camadas da vida social e material, bem como de múltiplos níveis de governança (nacional e, principalmente, local). Nesse sentido, busca compreender como o direito internacional passou a operar (e as aspirações globais de progresso e desenvolvimento passaram a se materializar) por meio dos processos, normas, corpos e artefatos que são comumente identificados como "domésticos", isto é, nacionais e locais, e cujo caráter internacional é invisibilizado pela Teoria Legal Tradicional. É a partir de uma abordagem antropológica e etnográfica da matéria, portanto, que Eslava procura compreender o direito internacional não somente como um construto ideológico, mas também como um fenômeno social com capacidade constitutiva, isto é, com capacidade para dar forma a distintas realidades e de operar justamente por meio dos espaços, das coisas e dos corpos que cria. Torna-se, assim, possível perceber como normas, processos, coisas, espaços e sujeitos tipicamente retratados como domésticos (cidades, cidadãos, leis urbanas, direitos, obrigações e serviços) acabam por carregar o "ethos" do direito internacional. ${ }^{1}$

De fato, segundo Eslava, desde o período colonial

1 ESLAVA, Luis. Local space, global life: the everyday operation of international law and development. Cambridge: Cambridge University Press, 2015. p. xiv-xvi. 
o direito internacional tem estado engajado na transformação das realidades e identidades dos sujeitos, "[...] shifting people's surroundings, their perception of themselves and their livelihoods worldwide" ${ }^{2}$. No contexto contemporâneo, diante do fenômeno da descentralização do desenvolvimento - que pode ser resumido como a transferência das responsabilidades governamentais e desenvolvimentistas dos governos centrais para as administrações locais — as realidades locais do Terceiro Mundo - sobretudo - continuam a ser transformadas de acordo com as prescrições normativas do direito internacional e do projeto neoliberal de governança global, que se fortaleceu a partir da década de 1990. Essa transformação, no entanto, é, agora, mediada pelas jurisdições locais (cidades, municípios e regiões metropolitanas), que passaram a exercer as funções de autoridade outrora exclusivas dos estados-nação. Apesar dessa aparente autonomia, no entanto, como demonstra o autor, as administrações locais continuam sujeitas a estruturas mais amplas de governança internacional, arcabouços normativos internacionais que são assimilados pelas autoridades locais e pela própria população e que acabam por reconfigurar os espaços urbanos, as identidades e a própria realidade das populações periféricas do Terceiro Mundo. De acordo com Eslava, inclusive, o crescente papel das administrações locais na promoção dos padrões globais de desenvolvimento constitui uma réplica do modelo imperialista de domínio indireto (indirect rule), idealizado pelo agente colonial britânico e membro da Comissão Permanente de Mandatos da Liga das Nações Frederick Lugard. Ao fazer tal referência, Eslava chama atenção para o uso da descentralização como mecanismo mais eficiente de controle sobre as populações periféricas. ${ }^{3}$

Nesse contexto, o livro demonstra como o novo sistema descentralizado de governança permitiu uma maior conexão entre as jurisdições locais e os fluxos econômicos internacionais, o sistema financeiro internacional e os padrões internacionais de desenvolvimento, implementando a prática colonial do domínio indireto no contexto da ordem jurisdicional internacional contemporânea. Assim, com foco no desenvolvimento recente de Bogotá, Eslava analisou, especificamente,

2 ESLAVA, Luis. Local space, global life: the everyday operation of international law and development. Cambridge: Cambridge University Press, 2015. p. xvii.

3 ESLAVA, Luis. Local space, global life: the everyday operation of international law and development. Cambridge: Cambridge University Press, 2015. p. 21. como a vida global está sendo materializada no espaço urbano da cidade por meio da configuração dos seu espaços, da formação dos sujeitos, de novos arranjos administrativos regulatórios, bem como de objetos mundanos (mapas, publicidades, postes de energia elétrica, entre outros).

O ponto de partida da discussão é uma interessante reflexão proposta por Eslava a partir de um mapa da cidade de Bogotá, elaborado por uma construtora transnacional com investimentos na cidade. Eslava percebe que, no mapa, Bogotá é retratada de forma distinta da realidade. Talvez com a intenção de "encantar" passageiros (consumidores) transnacionais e, assim, expandir os ganhos financeiros da construtora, o mapa apresenta a cidade de Bogotá em um fundo branco, omitindo, por um lado, a Colômbia (esse estado falido que contrasta com o sucesso do desenvolvimento urbano recente da capital) e, de forma ainda mais problemática, as habitações ilegais que cercam a cidade. Assim, a cidade é propositalmente retratada de modo fantasioso, como isolada dos conflitos do Estado colombiano e como livre de favelas (slum-free). Fazendo, então, uma analogia com o passado colonial, Eslava percebe que, no lugar da brutalidade dos conquistadores de outrora, hoje a violência se dá de modo mais sutil, como, por exemplo, a partir das abstrações, distorções e omissões da realidade da cidade perpetradas pelo referido mapa. Ademais, Eslava percebe que a representação fantasiosa de Bogotá trazida pelo mapa representa um projeto de cidade de acordo com os ideais globais de desenvolvimento. ${ }^{4}$ É a partir dessa reflexão que o autor dá início à discussão acerca da operação cotidiana do direito internacional.

\subsection{Estrutura do livro e resumo dos capítulos}

Local Space, Global Realities apresenta um estudo de caso acerca do processo recente de desenvolvimento urbano que vem transformando a cidade de Bogotá desde que a reforma da Constituição Colombiana de 1991 conferiu às jurisdições locais da Colômbia maior autonomia política, financeira e administrativa. Por um lado, o objetivo do livro é compreender a crescente relevância das cidades na ordem legal global e na construção de um novo modelo de nation-building - menos centralizado, mais dinâmico e competitivo, mais integra-

4 ESLAVA, Luis. Local space, global life: the everyday operation of international law and development. Cambridge: Cambridge University Press, 2015. p. 6. 
do aos fluxos globais de comércio e de investimento e mais alinhado aos padrões globais de desenvolvimento, progresso e sustentabilidade - e de governança global. Por outro, o livro busca entender como o processo global de descentralização - que se expandiu a partir da década de 1990, principalmente no Terceiro Mundo é exemplificado pela cidade de Bogotá, em especial pela maneira como a cidade tem lidado com seus bairros, assentamentos e moradias irregulares. ${ }^{5}$

O rápido processo de desenvolvimento urbano da cidade de Bogotá - desencadeado pelo movimento global de descentralização do desenvolvimento - é, portanto, usado como exemplo para demonstrar a presença do direito internacional e do desenvolvimento em cada aspecto da vida social e material local das cidades em processo de globalização — da configuração espacial à construção da identidade dos sujeitos e cidadãos. O objetivo é demonstrar que o direito internacional está, hoje, cada vez mais presente na vida administrativa diária das cidades. Para Eslava, o direito internacional é um componente ordinário para a constituição das relações sociais, particularmente naqueles lugares que foram sujeitos ao domínio colonial e são, hoje, objeto dos projetos globais de desenvolvimento: o Terceiro Mundo, ou Sul Global. ${ }^{6}$

O primeiro capítulo do livro (Introdução) apresenta as justificativas e objetivos do estudo, bem como a base bibliográfica utilizada para abordar a relação entre direito internacional e desenvolvimento. Em seguida, Eslava apresenta o escopo metodológico do estudo: um olhar etnográfico sobre o direito internacional e o projeto de desenvolvimento que permite perceber como ambos os fenômenos se tornaram presentes nas normas nacionais e locais, nas práticas administrativas e na "organização material e humana da vida local".?

O capítulo 2 (Building the global from the local) analisa o modo como o processo de descentralização do desenvolvimento e de internacionalização das cidades facilitou a transformação urbana da cidade de Bogotá,

5 Moradias irregulares (“illegal neighbourboods") são entendidas ao longo do livro como construções que não estão de acordo com as regulações e planos de desenvolvimento locais ou que são construídas em áreas de proteção ambiental, por exemplo).

6 ESLAVA, Luis. Local space, global life: the everyday operation of international law and development. Cambridge: Cambridge University Press, 2015. p. 33.

7 ESLAVA, Luis. Local space, global life: the everyday operation of international law and development. Cambridge: Cambridge University Press, 2015. p. 23. alterando a maneira com que a administração local lida com seus habitantes "ilegais". ${ }^{8} \mathrm{O}$ capítulo inicia com a análise de um discurso do ex-Secretário Geral da ONU, Kofi Annan, para o United Cities and Local Governments Summit (2005), no qual são discutidas as condições do processo de descentralização e o crescente protagonismo das cidades no âmbito global. ${ }^{9}$ Eslava demonstra que esse movimento de descentralização engendra uma série de elementos que fazem parte, na realidade, de uma estratégia mais ampla de governança global, comprometida com a construção de um cenário administrativo multidimensional mais apto a integrar novos atores globais e implementar as reformas neoliberais esperadas no contexto pós-Guerra Fria. Em resumo, o processo de descentralização é apresentado a partir de quatro perspectivas: 1) como resposta aos problemas do Terceiro Mundo e aos fracassos do modelo centralizado de desenvolvimento; 2) como parte de um projeto de construção de um cenário administrativo mais apto a integrar novos atores e a implementar reformas neoliberais; 3) como mais capaz de criar um cenário institucional legal mais apto a atender as demandas e necessidades da população, que pode inclusive ser integrada aos processos de decisão; e 4) como parte de uma tendência internacional para construção de uma ordem global que esteja além dos aparatos administrativos dos estados-nação. ${ }^{10}$

Na sequência, o capítulo narra como a Colômbia reconhecida como um Estado (quase) falido - adotou a descentralização a partir da reforma constitucional de 1991, e como a cidade de Bogotá, desde então, tem se desenvolvido em um ritmo impressionante. ${ }^{11}$ Buscando dar conta de como tais transformações fazem parte de

8 A nova abordagem utilizada pela administração local de Bogotá para lidar com seus habitantes "ilegais" compreende uma série de esforços por parte da administração local para controlar a expansão dos assentamentos e para regularizar os assentamos ilegais já existentes, como por exemplo, o fortalecimento institucional (instituição e cobrança de impostos), planejamento urbano, cadastro e mapeamento das populações "ilegais".

9 Conforme o referido discurso, devido à crescente urbanização do Terceiro Mundo, e à proximidade que as administrações locais têm em relação às pessoas sujeitas à sua autoridade, o papel e a responsabilidades das cidades na busca pelos objetivos globais de desenvolvimento deve ser valorizado.

10 ESLAVA, Luis. Local space, global life: the everyday operation of international law and development. Cambridge: Cambridge University Press, 2015. p. 68-70.

11 A partir da reforma constitucional de 1991, planejar e implementar o desenvolvimento dentro das municipalidades se tornou uma das estratégias primárias por meio da qual seria possível revitalizar o projeto de construção da nação colombiana. 
uma tendência mais ampla de reconstituir a forma dos estados-nação para criar uma nova ordem global que se manifeste por meio das jurisdições locais, Eslava apresenta um interessante paralelo entre o papel das cidades no contexto colonial e no contexto contemporâneo da descentralização. ${ }^{12}$ Para tal, retoma a já mencionada Teoria do Domínio Indireto de Lugard. ${ }^{13}$ Por fim, refletindo acerca da distinção existente entre os habitantes legais e ilegais da cidade de Bogotá, o autor conclui que este se trata de um antagonismo produtivo, uma vez que permite à administração local a reconstrução das áreas informais da cidade e das subjetividades dos seus habitantes de acordo com os valores e objetivos globais de desenvolvimento.

Nos capítulos 3 e 4, Eslava explica como a descentralização veio a se tornar o paradigma legal e administrativo por meio do qual as responsabilidades globais e nacionais de desenvolvimento foram alocadas para o âmbito das jurisdições locais, não somente na Colômbia, mas em todo o Terceiro Mundo. O capítulo 3 (Development and the nation-state) apresenta um estudo completo e abrangente acerca do paradigma do desenvolvimento, desde o período pós-guerra, quando o projeto do desenvolvimento é lançado, até a década de 1980, quando o papel do estado-nação enquanto agente do desenvolvimento passa a ser questionado. $\mathrm{O}$ autor demonstra como o discurso técnico, "atingível" e estadocêntrico do desenvolvimento, foi utilizado, em articulação com a nova ordem institucional internacional, para construir as nações do terceiro mundo, e como se tornou, nesse período, o termo mediador das relações norte-sul e a

12 Eslava demonstra como a descentralização atualizou e estendeu o papel tradicional desempenhado pelas cidades no contexto do imperialismo (do século XVI ao século XX). Em tal contexto, as cidades eram entendidas como locais para exercício da autoridade colonial, por meio dos quais as decisões das metrópoles irradiariam para toda a extensão do território colonial. Direcionando o enfoque para o contexto da Revolução Urbana de Bogotá, Eslava traça outro paralelo interessante: enquanto no período medieval europeu os muros serviam como demarcações espaciais que assinalavam a segurança e o perímetro de autoridade das cidades, excluindo desse âmbito os subúrbios e vilas que, embora fizessem parte da mesma jurisdição, mas estavam fora dos limites estabelecidos pelo muro, no contexto contemporâneo, os estatutos de desenvolvimento e de planejamento urbano, aliados aos mecanismos de controle dos perímetros municipais, passaram a desempenhar as mesmas funções outra desempenhadas pelos muros, nomeadamente: excluir parcela da população - vista como "ilegal" - do perímetro da legalidade, da segurança e da autoridade da cidade.

13 ESLAVA, Luis. Local space, global life: the everyday operation of international law and development. Cambridge: Cambridge University Press, 2015. p. 72. própria língua franca das relações internacionais. Nesse contexto, as teorias de Weber, Keynes e Rostow são apresentadas como representantes desse paradigma, que encontra no aparato burocrático nacional e na centralização da autoridade suas principais características. $\mathrm{Na}$ sequência, o capítulo narra as condições que levaram à exaustão do discurso do desenvolvimento, que reforçaram as dúvidas em relação ao estado-nação, e que deram ensejo ao surgimento de um novo paradigma intelectual (neoliberalismo) e de novos parâmetros e marcadores da política de desenvolvimento. Dentre os fenômenos que justificaram a descentralização, ou a "virada para o local", são mencionados, dentre outros, o aumento da urbanização e a desigualdade produzida pelos modelos tradicionais (nacionais) de desenvolvimento. Por fim, o capítulo descreve como essa narrativa - da centralização à descentralização — se deu no contexto da Colômbia.

No capítulo 4 (Development changes places), Eslava descreve como a ideia de descentralização transformou o discurso do desenvolvimento, introduzindo as jurisdições locais como um novo nível de governança e provocando, assim, um processo global de "reterritorialização do exercício da autoridade". ${ }^{14}$ Visando melhor compreender a dimensão global desse processo, Eslava retoma a Teoria do Domínio Indireto (indirect rule), de Frederick Lugard, que demonstra como os sistemas descentralizados e indiretos de governança permitiam (à metrópole) uma administração mais efetiva e eficiente dos territórios periféricos. Para Lugard, segundo Eslava, estruturas administrativas decentralizadas e mecanismos indiretos de domínio seriam uma maneira eficiente para extrair o máximo, em termos econômicos, da população nativa, enquanto as mantinham "enquadradas em estruturas internacionais mais amplas de governança". ${ }^{15}$ Fica claro, nesse contexto, que Eslava procura traçar um paralelo entre o domínio indireto como prática colonial do imperialismo e a descentralização como uma espécie

14 A descentralização é apresentada como uma tentativa de recuperar a promessa do desenvolvimento no Terceiro Mundo, mudando o foco tradicional do crescimento econômico, produtividade e gestão macroeconômica para o âmbito do planejamento urbano, das leis administrativas, da responsabilidade fiscal, das políticas de incentivo ao mercado e ao investimento estrangeiro, de "boa governança", do respeito aos direitos humanos (sobretudo os direitos de propriedade privada e dos contratos), da proteção ambiental, entre outros).

15 ESLAVA, Luis. Local space, global life: the everyday operation of international law and development. Cambridge: Cambridge University Press, 2015. p. 143. 
de prática neocolonial do imperialismo contemporâneo.

O capítulo 4 também apresenta a trajetória do princípio da descentralização no contexto do direito internacional e das leis nacionais da Colômbia. ${ }^{16}$ Eslava alerta, no entanto, para o fato de que, na Colômbia, assim como no resto do Terceiro mundo, essa nova atenção política para as jurisdições locais foi acompanhada (e facilitada) pela onda de reformas neoliberais estruturais comprometidas com o desmanche dos mecanismos nacionais de controle central das economias do Terceiro Mundo, um argumento que reforça a ideia de que o processo de descentralização sob análise possui um caráter neocolonial. ${ }^{17}$ Nesse sentido, são apresentados alguns paradoxos que resultam do processo de descentralização, que dizem respeito, sobretudo, ao aumento de responsabilidades contraditórias transferidas para as administrações locais. ${ }^{18}$ Por fim, após demonstrar a importância internacional do planejamento espacial e territorial como uma ferramenta efetiva para materializar as aspirações e ideais de desenvolvimento no contexto local, Eslava introduz as tecnologias e regulações utilizadas pela cidade de Bogotá para promover o desenvolvimento local. ${ }^{19}$ São apresentadas ferramentas regulatórias de planejamento espacial ("estratégia territorial") que permitem à administração local de Bogotá repensar seus espaços urbanos, reformando as realidades locais de acordo com seus objetivos de desenvolvimento. ${ }^{20}$

16 Os instrumentos legais internacionais que reconhecem a importância crescente das administrações locais para o desenvolvimento o fazem no âmbito do direito urbano e do direito à cidade, fato que é sintomático dos níveis crescentes de urbanização em todo o mundo.

17 ESLAVA, Luis. Local space, global life: the everyday operation of international law and development. Cambridge: Cambridge University Press, 2015. p. 149.

18 Ao mesmo tempo em que devem estar comprometidas com valores democráticos, direitos humanos e proteção ambiental, as municipalidades devem também seguir princípios como sustentabilidade demográfica e financeira e planejamento integral para se tornarem economicamente dinâmicas, internacionalmente competitivas, financeiramente solventes e auto dependentes. Há, portanto, paradoxalmente, a necessidade de sincronizar um aparato burocrático mais eficiente e obrigações de disciplina econômica estrita (crescimento, disciplina fiscal e competitividade internacional) com a promoção de políticas progressistas que estejam de acordo com os novos ideais (globais) de progresso social, ambiental, cultural e fiscal.

19 ESLAVA, Luis. Local space, global life: the everyday operation of international law and development. Cambridge: Cambridge University Press, 2015, p. 162-163.

20 ESLAVA, Luis. Local space, global life: the everyday operation of international law and development. Cambridge: Cambridge University Press, 2015, p. 166-170. Os exemplos de ferramentas regu-
O capítulo 5 (The making of a new Bogotâ) apresenta a situação dos residentes ilegais de Bogotá, procurando compreendê-los como sujeitos excluídos ou marginalizados que estão, todavia, envolvidos em uma dinâmica de formação que gravita ao redor de categorias legais e narrativas de desenvolvimento conectadas com um exercício administrativo global. O capítulo narra as estratégias utilizadas pela cidade para conter o avanço dos assentamentos ilegais e para integrar os assentamentos existentes na vida "oficial" da cidade. São discutidas as seguintes estratégias: o trabalho coletivo de departamentos administrativos e entidades provedoras de serviços públicos, o uso de sofisticados métodos cartográficos (como a Matriz Operativa, o banco de dados implementado pelo escritório de inspeção), novos artefatos de governança (como as normas de planejamento urbano e espacial já mencionadas), e o fortalecimento institucional, representado pelo aumento da arrecadação oriunda da formalização de territórios e da expansão da base contribuinte. A atenção especial que o projeto de reconstrução da cidade de Bogotá dedica ao controle da formação espacial da cidade, bem como da população, é apresentado como exemplo de como os compromissos globais e as prescrições normativas de desenvolvimento internacional se cristalizam no âmbito local, direcionando a vida coletiva das populações. O processo de legalização é, nesse contexto, analisado como o principal instrumento utilizado pela administração local para atualizar sua autoridade em relação à periferia, e para reconstituir a identidade desses sujeitos como habitantes "oficiais" da cidade. Como explica Eslava, os residentes das habitações ilegais incluídos no processo de legalização são objetos de um exercício pedagógico de autoridade que procura neles incutir novos tipos de valores (globais), novas responsabilidades (fiscais) e novas consciências no nível de suas subjeti-

latórias de planejamento espacial apresentadas por Eslava são: o $\mathrm{Or}$ denamiento Territorial da Constituição Colombiana, o Plano Nacional de Desenvolvimento e a Lei de Ordenamento Territorial, que dá as diretrizes para que os municípios desenvolvam seus próprios Planos de Desenvolvimento Local e Planos de Ordenamento Territorial. Além das ferramentas regulatórias mencionadas, que demonstram o papel cada vez mais importante desempenhado pelo direito na busca pelo desenvolvimento, os mapas são outro tipo de ferramenta para controle, planejamento e criação do espaço urbano apresentados por Eslava. Cabe mencionar, ainda, nesse sentido, que, após analisar o importante papel desempenhado pelos mapas na construção de impérios coloniais e de nações, Eslava analisa o papel constitutivo representado pelos mapas no contexto do planejamento urbano contemporâneo de Bogotá, principalmente as implicações da representação das áreas de habitação legais e ilegais nos mapas da cidade. 
vidades (cidadania). ${ }^{21}$ Em suma, "ser [e tornar-se] legal ou ilegal posiciona os sujeitos na escada da civilização Ocidental, da modernidade e da humanidade". Assim, o processo de legalização pode ser visto como um "rito de passagem" da ilegalidade para a legalidade, que busca "conciliar o passado e a cultura ilegal dos indivíduos com os novos padrões de civilidade definidos pela cidade, suas leis, seus recentes compromissos internacionais e aspirações de desenvolvimento". Dessa forma, Eslava demonstra de que maneira a ideia de desenvolvimento está, hoje, imbricada no conceito de legalidade: "To be lawful today means to be developed, and vice versa: to be illegal is to be underdeveloped." 22

Importa perceber, contudo, que esse novo arcabouço normativo-administrativo não impede a urbanização ilegal, mas cria a capacidade administrativa para identificar as ilegalidades e tomar atitudes necessárias para remediar a situação. A distinção entre legais e ilegais é mantida enquanto a situação não for resolvida. Assim, se, por um lado, o processo de legalização pode ser entendido como uma importante avenida para o avanço da ordem institucional, administrativa e financeira da cidade, por outro lado, como explica Eslava, é um procedimento técnico, apolítico e burocrático que, em razão disto, acaba por suprimir o papel da política, tipicamente usado para articular as demandas e necessidades sociais, já que os residentes que desejam se legalizar devem se submeter ao processo burocrático proposto pela administração local e acabam por abandonar sua relação politizada e seus laços de solidariedade com a cidade e demais habitantes. ${ }^{23}$

O capítulo 6 (The local self of international), por sua vez, amplia o escopo da discussão, apontando, a partir dos processos administrativos locais acima descritos, os elementos da operação cotidiana do direito internacional. Contrapondo-se à Teoria do Império de Hardt e Negri (que concebe o Império contemporâneo como um fenômeno global e desterritorializado), Eslava apresenta uma visão da ordem global como "um fenômeno espacialmente e legalmente enraizado, onde as adminis-

21 ESLAVA, Luis. Local space, global life: the everyday operation of international law and development. Cambridge: Cambridge University Press, 2015. p. 50-51.

22 ESLAVA, Luis. Local space, global life: the everyday operation of international law and development. Cambridge: Cambridge University Press, 2015. p. 173.

23 ESLAVA, Luis. Local space, global life: the everyday operation of international law and development. Cambridge: Cambridge University Press, 2015. p. 233. trações locais desempenham um papel fundamental". ${ }^{24}$ Assim, o autor identifica o surgimento de uma nova forma de disciplina internacional, que opera por meio do crescente uso da autoridade pelas administrações locais. Nesse sentido, Eslava percebe que, em função da descentralização, desencadeou-se um processo de difusão da soberania. Como resultado, esta se manifesta, hoje, de modo disperso por meio das instituições internacionais, dos Estados e dos municípios. Enfim, por meio de múltiplos regimes (públicos e privados) e níveis de governança, constituindo "um complexo conjunto normativo-jurisdicional internacional" ${ }^{25}$

Dessa forma, refutando a concepção tradicional segundo a qual o "municipal" é visto como subsidiário ao nacional, além de completamente desconectado do internacional -, Eslava demonstra como o "local" e o "nacional" dialogam constantemente com o "internacional" (normas internacionais relacionadas ao processo de desenvolvimento). Eslava demonstra de que maneira ocorre a "reincorporação da autoridade internacional dentro dos corpos jurisdicionais locais e suas ações", ou, em outras palavras, como o internacional se torna doméstico. Esse fenômeno é identificado pelo autor como a "rotinização" local do internacional" ("local routinization of the international'), que transforma os oficiais administrativos locais em verdadeiros agentes da globalização e que deposita nos residentes locais as obrigações e ambições globais de desenvolvimento. Como resultado, prevalece uma forma de administração do território e das populações urbanas "mediada", por meio do direito, entre múltiplos níveis de governança: do local ao internacional. ${ }^{26}$

Após refletir acerca do papel instrumental desempenhado pelo direito na organização dos espaços e na constituição da cidadania, o capítulo aborda também o papel do direito enquanto linguagem, meio através do qual as contradições urbanas são expressas e a política ocorre. Contrapondo-se à concepção majoritária, que associa a presença do direito ao progresso, Eslava re-

24 HARDT, Michael; NEGRI; Antonio. Empire. Cambridge: Cambridge University Press, 2000. ESLAVA, Luis. Local space, global life: the everyday operation of international law and development. Cambridge: Cambridge University Press, 2015. p. 238.

25 ESLAVA, Luis. Local space, global life: the everyday operation of international law and development. Cambridge: Cambridge University Press, 2015. p. 248.

26 ESLAVA, Luis. Local space, global life: the everyday operation of international law and development. Cambridge: Cambridge University Press, 2015. p. 250-251. 
lembra que, historicamente, o direito desempenhou papel central para a construção e organização dos impérios, das colônias e do mundo contemporâneo, por assim dizer. O que há de novo hoje, contudo, é que as aspirações globais do direito buscam ser efetivadas por meio das jurisdições locais, em um processo identificado como "reprodução legal paralela". Em razão desse fenômeno, Eslava afirma que "se tornou praticamente impossível distinguir onde o internacional termina e o local começa, e quando a disciplina internacional se torna local".

Em seguida Eslava aponta para o importante fato de que a ordem global e seu sistema normativo e jurisdicional opera pelo mundo em diferentes níveis de intensidade, impactando, de forma irregular, sobre a geografia global. Nas nações do Terceiro Mundo (ex-colônias que ocupam posições de dependência no sistema político e econômico global), as pressões internacionais se mostram de forma muito intensa (na forma "nacional" da suas existências pós-coloniais, nas condicionalidades impostas pelas organizações internacionais, e na pressão para desenvolver-se de acordo com os padrões globais), ao passo que as nações ricas, por outro lado, possuem mais "espaço para manobra" no que diz respeito a tais imposições globais, seja devido a sua força industrial e financeira, seja devido ao seu papel histórico na criação do sistema internacional legal. Em razão dessa incidência irregular, Eslava identifica duas consequências: o fato de que algumas parcelas da população global estão mais expostas à pressão internacional do que outras; e o fato de que, nos lugares onde a pressão internacional é sentida com maior intensidade, o "internacional" acaba por permear as normas e práticas administrativas nacionais e locais com maior facilidade. ${ }^{27}$ Conclui-se, assim, que o Sul Global está, de fato, muito mais próximo ao "internacional", isto é, muito mais sujeito aos imperativos da globalização e à influência do direito internacional do que o Norte. ${ }^{28}$

27 ESLAVA, Luis. Local space, global life: the everyday operation of international law and development. Cambridge: Cambridge University Press, 2015. p. 254-257.

28 Nesse ponto, se manifesta o engajamento da obra em análise com a crítica de terceiro mundo do direito internacional. Isto porque, além de identificar a desigualdade internacional existente entre Norte e Sul, Eslava apresenta uma interpretação da relação contemporânea entre o "local" e o "internacional" como uma maneira velada de promover nada mais do que o desenvolvimento econômico privado, em um contexto no qual a dificuldade de responsabilização das Instituições internacionais e das Corporações Transnacionais permanece uma realidade.
Por fim, o capítulo 6 traz à tona a questão da resistência. Eslava começa explicando que as estratégias de organização territorial levadas a cabo pela administração local de Bogotá (processo de legalização) resultaram, entre outras coisas, na fragmentação das discussões políticas em termos de solidariedade de classe e de alianças entre os moradores, o que, por sua vez, acabou por despolitizar as comunidades. Nesse contexto, Eslava identifica um paradoxo trazido à tona pelo processo burocrático de legalização: ao mesmo tempo em que trouxe mais visibilidade e participação aos moradores, lhes ofereceu menos capacidade de influenciar, substancialmente, o poder público em favor de suas demandas. Isso ocorre, porque a legalização é, na realidade, um procedimento técnico e despolitizado, que não necessariamente resolve as demandas sociais ou realiza a justiça social.

Em seguida, Eslava ilustra as múltiplas formas de resistência que, nos anos recentes, têm contestado o processo de desenvolvimento de Bogotá. São apresentados três exemplos: o ativismo de base desempenhado pela Red Popular Ambiental de Territorialidades del Distrito Capital $^{29}$; as marchas e manifestações (rallies) organizadas por líderes populares dos bairros e de movimentos de base $^{30}$; e as iniciativas de desenvolvimento alternativo ${ }^{31}$.

29 Com enfoque na promoção da justiça social e ambiental, o ativismo de base desempenhado pela Red Popular se insurge contra a organização espacial promovida pelo Planos de Organização Territorial de Bogotá. A resistência busca reforçar a soberania da comunidade sobre os territórios ilegais, desmistificando a tecnicidade do desenvolvimento através de ferramentas cartográficas e burocráticas oferecidas pela cidade.

30 O segundo tipo de resistência oferecida pela população Bogotana ao processo de desenvolvimento diz respeito às marchas e manifestações (rallies), organizadas por líderes populares de movimentos de base, inclusive da Red Popular que integram diversos bairros da cidade. O objetivo dessas manifestações é conscientizar os residentes de Bogotá acerca dos problemas que afetam tanto os habitantes legais quanto os ilegais e que não são solucionados pela administração da cidade. Os problemas incluem: a falta de segurança das ruas, a falta de oportunidades de emprego, as deficiências da estrutura pública de transporte, a falta de uma infraestrutura pública adequada e a violência contra determinados grupos sociais perpetradas tanto por grupos criminosos quanto por forças oficias de segurança.

$31 \mathrm{O}$ terceiro tipo de resistência diz respeito às tentativas de criar formas alternativas de desenvolvimento na cidade, especialmente em áreas (legais e ilegais) que ainda não foram afetadas pelo desenvolvimento da cidade. Evitando o linguajar jurídico e oficial do processo de legalização, esse tipo de resistência procura promover programas comunitários, bem como novas e variadas ideias destinadas à melhoria das condições de vida da população. O objetivo é fomentar a agência e o espírito comunitário dos residentes, enfatizando a ideia de soberania comunitária bem como projetos de micro-desenvolvimento. Eco-bairros, casas e cozinhas comunitárias, 
Nesse sentido, o autor finaliza com uma importante reflexão acerca da necessidade de compreender as mecânicas locais e efeitos cotidianos do direito internacional e do desenvolvimento, bem como as formas (oblíquas) de resistência ao projeto de desenvolvimento promovidas pelos movimentos de base no âmbito local. Nas palavras de Eslava,

[...] questions about how authority is performed and responsibility distributed in today's global order should be analysed concomitantly with questions regarding the manner in which such modes of authority and assignations of responsibility are resisted. ${ }^{32}$

Como explica o autor, somente com base na análise das múltiplas formas de resistência e do reconhecimento da dimensão local do direito internacional é possível compreender os efeitos negativos do processo de reorganização da jurisdição global analisado ao longo do livro, vislumbrar e fortalecer modos de resistência e, principalmente, engajar a academia do direito internacional para a mudança das condições de vida daqueles que mais precisam. Nas palavras do próprio autor,

Only by refining our understanding of the way in
which international law operates beyond its typical
normative and institutional sites and modes of
representation will it become possible to appreciate
and contribute to the many ways in which ordinary
people, like the community leaders in Bogotá,
engage with the spaces, legal forms and frames
produced by the international normative order. ${ }^{33}$

É nesse sentido que o capítulo 7 conclui o livro sob análise, reforçando a ideia da necessidade de transformar a compreensão e o estudo do direito internacional e do desenvolvimento de acordo com as necessidades materiais e a vida real das pessoas, abandonando, assim, as leituras ortodoxas, estadocêntricas e desterritorializadas desses fenômenos.

\subsection{O método: um olhar etnográfico sobre o direito internacional}

Um dos pontos mais importantes da obra - que representa, pode-se dizer, uma verdadeira inovação no

atividades culturais, jardins comunitários e grupos de ação ambiental são das iniciativas de desenvolvimento alternativo promovidas por esses grupos.

32 ESLAVA, Luis. Local space, global life: the everyday operation of international law and development. Cambridge: Cambridge University Press, 2015. p. 280.

33 ESLAVA, Luis. ESLAVA, Luis. Local space, global life: the everyday operation of international law and development. Cambridge: Cambridge University Press, 2015. p. 290. que diz respeito à maneira de enxergar a presença diária do direito internacional nos múltiplos níveis de governo que hoje implementam o desenvolvimento - é o método antropológico-etnográfico por ele desenvolvido para compreender as complexidades da ordem legal contemporânea e as contradições implicadas no processo de descentralização. Buscando responder às provocações de Hilary Charlesworth ${ }^{34}$ — no sentido de "refocalizar o direito internacional em questões de justiça estrutural que subjazem a vida quotidiana" e de imaginar, portanto "como seria o direito internacional da vida quotidiana" - Eslava empregou uma abordagem etnográfica para estudar a operação do direito internacional e do projeto de desenvolvimento no contexto do (crescente) interesse atual nas jurisdições locais. Dentre as razões que o levaram a optar por esse método, Eslava destaca quatro vantagens: (1) capacidade para integrar uma rica pluralidade de fontes e materiais - de materiais oficias internacionais à entrevistas com residentes $\mathrm{e}$ oficiais da administração local de Bogotá; (2) capacidade para identificar e problematizar a presença do direito internacional nos âmbitos nacional e local, bem como (3) para perceber como este, juntamente ao projeto de desenvolvimento está constantemente estruturando o mundo físico e social; e, por fim, (4) a capacidade que o método proporciona para engajar ética e politicamente, para repensar a prática acadêmica e para pensar modos de resistência à globalização e ao desenvolvimento. ${ }^{35}$

Segundo Eslava, o olhar etnográfico permite compreender o direito internacional não como um corpo de regras isolado, produzido por instituições hierarquicamente superiores ou como um conjunto de relações diplomáticas dentro de um universo estático e estadocêntrico, mas como um "sistema institucional e normativo em expansão que carrega dentro de si uma bagagem material [...] muito particular", e que, trespassando diversos níveis jurisdicionais, está constantemente engajado na estruturação das relações sociais e materiais. O método permite, assim, ver o direito internacional não como um mero projeto normativo e ideológico, mas como "um projeto que busca sua cristalização nos planos materiais e subjetivos do mundo", isto é, no dia a dia da vida das pessoas comuns. ${ }^{36}$

34 CHARLESWORTH, Hilary. International law: a discipline of crisis. Modern Law Review, v. 65, n. 3, p. 377-392, 2002.

35 ESLAVA, Luis. Local space, global life: the everyday operation of international law and development. Cambridge: Cambridge University Press, 2015. p. 30.

36 ESLAVA, Luis. Local space, global life: the everyday operation of 


\subsection{Reflexões críticas}

Em um contexto no qual a vida nas cidades adquire um papel cada vez mais central na ordem legal global, Local Space, Global Life projeta um novo olhar sobre o direito internacional e sobre o projeto de desenvolvimento. O livro propõe uma (re)leitura do direito internacional a partir de sua realidade material, isto é, de sua operação cotidiana. No esforço intelectual para a execução dessa tarefa, o autor faz uso de uma ampla diversidade de fontes e mídias, como fotos da cidade de Bogotá e transcrições de entrevistas com residentes da cidade, o que é atípico no contexto tradicional do direito internacional. Como resultado, tem-se um livro cujo estilo é bastante singular e cuja forma é, indubitavelmente, inovadora.

Merecem menção também as analogias traçadas entre os contextos colonial e contemporâneo, sobretudo, nesse caso, as referências ao conceito de "domínio indireto" de Lugard. Tais reflexões teóricas a respeito da continuidade do colonialismo no contexto atual são de incontestável valor para as abordagens críticas do direito internacional que se dedicam ao estudo da relação entre direito internacional, colonialismo e imperialismo (principalmente as abordagens de terceiro mundo do direito internacional - TWAIL). Nesse mesmo sentido, o método antropológico e etnográfico desenvolvido por Eslava representa uma importante contribuição para a crítica do direito internacional, na medida em que contribui para uma reformulação teórica da disciplina a partir dos povos e classes oprimidos e necessitados do terceiro mundo. Mais precisamente, devido ao seu enfoque nas formas de resistência apresentadas pelos residentes de Bogotá, Local Space, Global Life se destaca como uma importante contribuição para repensar, nos termos de Rajagopal, o direito internacional a partir da resistência dos movimentos sociais do terceiro mundo, ou seja, para repensar o direito internacional "from below". ${ }^{37}$

Outro aspecto de relevante interesse, principalmente para os leitores brasileiros, diz respeito ao fato de que, embora restrita ao processo de desenvolvimento urbano da cidade de Bogotá, a análise de Eslava se aplica a qualquer das (muitas) cidades do Terceiro Mundo que

international law and development. Cambridge: Cambridge University Press, 2015. p. 25.

37 RAJAGOPAL, Balakrishnan. International law from below: development, social movements and third world resistance. Cambridge: Cambridge University Press, 2003. passam por processo semelhante de internacionalização. Os exemplos mais emblemáticos citados pelo próprio autor são: Nova Délhi, Istambul e Rio de janeiro.

Assim como em Bogotá, o problema do Rio de Janeiro em relação às habitações urbanas irregulares é histórico. Como um país de Terceiro Mundo, o processo de urbanização das principais cidades do Brasil também se deu de modo desordenado, principalmente em razão da extrema desigualdade socioeconômica dentro das cidades e, também, entre as regiões do país. Desse modo se deu a formação urbana do Rio de Janeiro, com a emblemática presença das favelas, em gritante contraste com os condomínios de luxo de alguns de seus bairros mais nobres. Assim como na Colômbia, a Constituição brasileira mais recente, também, atribuiu maior protagonismo aos municípios. Desde então, assim como Bogotá, a cidade do Rio de Janeiro tem concentrado esforços para reorganizar sua soberania em relação ao território e população. Essa tensão existente entre a vida local dos residentes ilegais da cidade e as pretensões globais de desenvolvimento se tornaram mais evidentes nos últimos anos, com a instituição das Unidades de Polícia Pacificadora (UPPs), com presença militar nas favelas e, principalmente, no contexto dos eventos internacionais sediados pela cidade. De fato, para se adequar aos padrões exigidos pelas entidades internacionais responsáveis pelos eventos que a cidade recentemente foi sede (Copa do Mundo de Futebol e Olimpíadas, em 2014 e 2016, respectivamente) a cidade do Rio de Janeiro foi objeto de uma intensa reorganização espacial de seus territórios. Por exemplo, para adequar a cidade aos padrões internacionais da FIFA (entidade responsável pela organização da Copa do Mundo de futebol), populações assentadas irregularmente em áreas tidas como estratégicas para a execução do evento, foram removidas forçadamente, como ocorreu no caso da remoção forçada de indígenas da Aldeia Maracanã, no ano de 2013. Para o jurista brasileiro, portanto, pode ser interessante tentar estabelecer um paralelo entre os efeitos da internacionalização das cidades de Bogotá e do Rio de Janeiro (bem como de muitas outras cidades brasileiras).

\section{Considerações finais}

Na medida em que propõe uma leitura mais mundana e aplicada do direito internacional, e que propicia um 
novo método para lidar com os principais desafios enfrentados pelas populações periféricas urbanas do Terceiro Mundo no contexto da globalização, Local Space, Global Life renova a crítica de terceiro mundo do direito internacional, readaptando-a ao contexto contemporâneo das cidades e de seus habitantes, isto é, ao contexto da vida real, subjetiva e material das pessoas. Por essa razão, é possível afirmar que o livro possui inegável relevância para o estudo crítico do direito internacional. Sua leitura é, portanto, recomendada a todos aqueles juristas comprometidos com a construção de uma ordem internacional mais justa e de um direito internacional mais favorável a populações destituídas e periféricas do mundo.

\section{REFERÊNCIAS}

CHARLESWORTH, Hilary. International law: a discipline of crisis. Modern Law Review, v. 65, n. 3, 2002.

ESLAVA, Luis. Local space, global life: the everyday operation of international law and development. Cambridge: Cambridge University Press, 2015.

HARDT, Michael; NEGRI; Antonio. Empire. Cambridge: Cambridge University Press, 2000.

LUGARD, Frederick. The dual mandate in British Tropical Africa. Londres: W. Blackwood \& Sons, 1922.

RAJAGOPAL, Balakrishnan. International law from below: development, social movements and third world resistance. Cambridge: Cambridge University Press, 2003. 
Para publicar na Revista de Direito Internacional, acesse o endereço eletrônico www.rdi.uniceub.br ou www.brazilianjournal.org.

Observe as normas de publicação, para facilitar e agilizar o trabalho de edição. 